Folia Hort. 26/2 (2014): 79-90

DOI: 10.2478/fhort-2014-0008
Published by the Polish Society

for Horticultural Science since 1989

\title{
Grafted vegetables - the influence of rootstock and scion on postharvest quality
}

\author{
Elazar Fallik ${ }^{1 *}$, Zoran Ilic ${ }^{2}$ \\ ${ }^{1}$ Department of Postharvest Science of Fresh Produce \\ ARO - the Volcani Center \\ Bet Dagan 50250, Israel \\ ${ }^{2}$ Faculty of Agriculture Pristina-Lesak \\ 38219 Lešak, Serbia
}

\begin{abstract}
Grafting of vegetable seedlings is a unique horticultural technology, practised for more than 50 years, to overcome problems associated with intensive cultivation on limited arable land. Grafting vegetables can protect against soil-borne diseases and nematodes, against abiotic stresses such as high/low temperatures, salinity, drought or excessive soil-water content, and against elevated soil concentrations of heavy metals and organic pollutants. In addition, the grafted plant takes up water and nutrients from the soil more efficiently and retains its vitality for longer periods during the growing season. However, rootstock/scion combinations may affect and alter the final size, yield, and quality of fruits from grafted plants, both immediately postharvest and during prolonged storage. These alterations may be attributed in part to differing production environments and methods, the type of rootstock/scion combinations used, and harvest date.

The aim of this paper is to review the most recent literature on the effects of grafting on postharvest quality of fruits/vegetables: tomato, watermelon, melon, eggplant, cucumber and pepper. The review will conclude by identifying several prospects for future research aimed at improving the quality of grafted fruit/vegetable products.
\end{abstract}

Key words: grafting methods, shelf life, sensory

\section{Abbreviations:}

CFI - chlorophyll fluorescence imaging, Chl - chlorophyll, dpa - days post-anthesis, HIG - hole-insertion grafting, IPM - integrated pest management, MAP - modified atmosphere packaging, SIG - side grafting, TA - titratable acidity, TAG - tongue approach grafting, TSS - total soluble solids

\section{INTRODUCTION}

Environmental stresses present the most limiting conditions for horticultural productivity and plant exploitation worldwide. Important environmental stress factors include: water, temperature, nutrition, light, oxygen availability, metal-ion concentrations, and pathogens (Colla et al. 2010, Savvas et al. 2010). A specific method of modifying plants to resist environmental stresses comprises grafting commercial cultivars onto selected vigorous rootstocks (Lee and Oda 2003). Grafting is nowadays regarded as a rapid alternative to the relatively slow methodology of breeding for 
increased environmental-stress tolerance of fruit vegetables (Flores et al. 2010). Grafting of vegetable seedlings is a unique horticultural technology, practised for more than 50 years in East Asia to overcome problems associated with intensive cultivation on limited arable land. This technology was introduced to Europe and other countries in the late $20^{\text {th }}$ century, along with improved grafting methods suitable for commercial production of grafted vegetable seedlings. Later, grafting was introduced to North America from Europe and it is now attracting increasing interest from both greenhouse growers and organic producers (Kubota 2008).

The advantages of grafting, a popular and valuable technique used for years in the production of vegetables, are unquestionable, one of the most important being protection against soil-borne diseases and nematodes (Louws et al. 2010). Until recently such problems were combated with soil fumigants such as methyl bromide, which has been banned; however, extensive efforts have been invested in searching for alternatives to fit into the new integrated pest management (IPM) systems (Louws et al. 2010). Another important advantage of grafting is protection against abiotic stresses such as high/low temperatures, salinity (Colla et al. 2010, Sánchez-Rodríguez et al. 2014), drought or excessive water soil content (Schwarz et al., 2010) and elevated concentrations of heavymetal and organic pollutants in soils (Savvas et al.
2010). Furthermore, grafting is very popular among farmers because it results in fruit yield increases and enhanced overall plant vigour. The grafted plant takes up water and nutrients from the soil more efficiently, and retains its vitality for longer periods during the growing season (Aloni et al. 2010, Lee et al. 2010). However, rootstock/scion combinations affect final size, yield and quality of fruits from grafted plants, both immediately postharvest and during prolonged storage (Figures 1 and 2). Several conflicting findings have been published on changes in fruit quality caused by grafting, and on whether these effects are advantageous or deleterious (Davis and Perkins-Veazie 2005-2006, Alexopoulos et al. 2007, Flores et al. 2010, Rouphael et al. 2010, Bekhradi et al. 2011, Kyriacou and Soteriou 2012). It is not surprising that rootstocks have such a drastic impact on the scion and its fruit; they can enhance plant vigour, improve disease resistance, improve tolerance of low soil temperatures and/or soil salinity, and improve uptake of soil nutrients and water. Additionally, studies have shown that RNA, proteins, and small molecules, some of which mediate signal transduction, can translocate from the rootstock to the scion, and thereby directly affect scion physiology (Liu et al. 2013, Tsaballa et al. 2013). The differences in reported results may be attributable in part to differences among production environments and methods (e.g., soilless vs. insoil culture, irrigation, and fertilization), types of rootstock/scion combinations, and harvest dates.

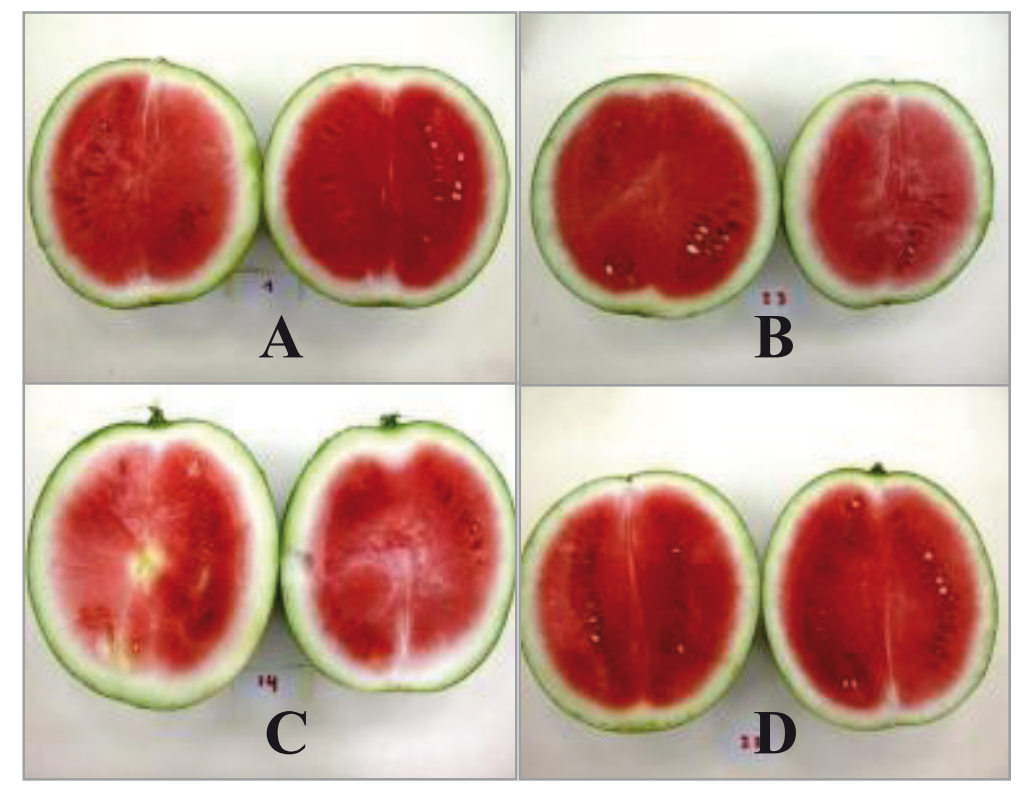

Figure 1. The influence of grafting on mini-watermelon 'Extazy' fruit quality: (A) non-grafted; (B) self-grafted; (C) 'Extazy' grafted on watermelon 'BDA' rootstock; (D) 'Extazy' grafted on watermelon 'PI-1609'rootstock (source - Eli Fallik) 


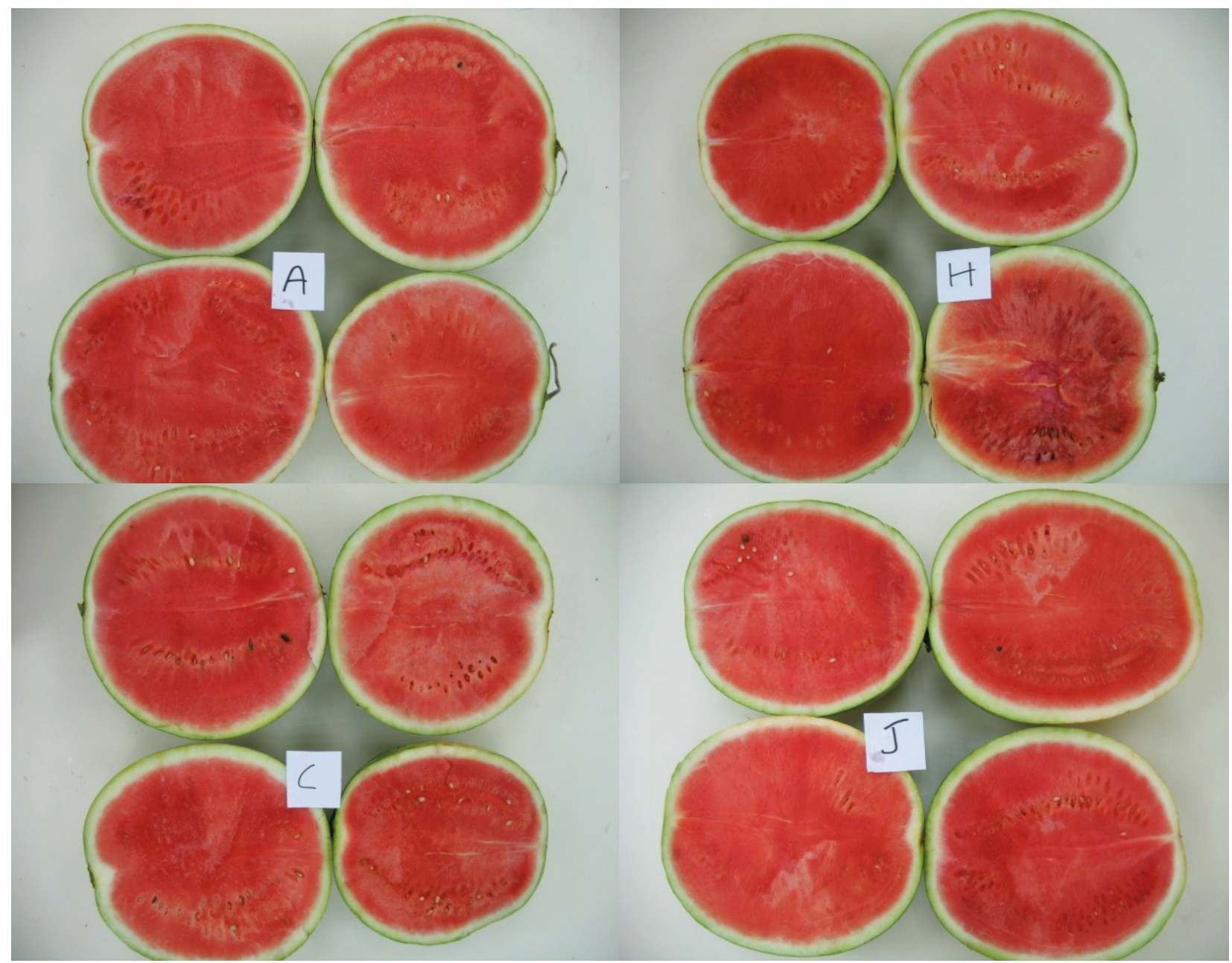

Figure 2. The relationship between rootstock and scion: A - watermelon cultivar 1262 (scion) grafted on 'BS1'; C - watermelon cultivar 1262 (scion) grafted on 'TZ-148'; H - watermelon cultivar 313 (scion) grafted on 'BS1'; J - watermelon cultivar 313 (scion) grafted on 'TZ-148' (source - Eli Fallik)

Moreover, the rootstock/scion combination may alter the amounts of hormones produced and their influence on the sex expression and flowering order of grafted plants (Aloni et al. 2010). According to Rouphael et al. (2010), modification of hormone status and water and nutrient uptake in grafted vegetables by specific rootstocks may lead to changes in cellular morphology, cell turgor, and cell-wall characteristics which, in turn, affect fruit firmness.

Increasing consumer demand for high-quality vegetable crops makes it essential to carefully select rootstock/scion combinations that can ensure highquality fruits. Therefore, the aim of the present paper is to review the most recent literature on the effects of grafting on postharvest fruit-vegetable (tomato, watermelon, melon, eggplant, cucumber and pepper) quality. The review will conclude by identifying several possible avenues for future research that aims to improve the quality of grafted vegetable products.

\section{GRAFTING METHODS}

Different grafting techniques are adopted for different scions and rootstocks; they depend on grafting objectives, farmers' experience, and postgrafting management conditions; and, moreover, the survival rate of grafted plants depends on compatibility between scion and rootstock, quality and age of seedlings, quality of the joined section, and post-grafting management. The grafting technique influenced the graft survival rate, with higher values recorded with splice grafting (78\%) than with cleft grafting (73\%) (Temperini et al. 2013). When scion and rootstock have hollow hypocotyls, the hole insertion and one-cotyledon grafting methods are preferred (Hassell et al. 2008), but the tongue-approach and cleft techniques, which have high survival rates, are often chosen by inexperienced farmers who have plenty of space and adequate labour whereas, in contrast, the onecotyledon and the hole-insertion techniques require 
experienced labour, specialized tools, and a healing chamber to obtain high survival rates. The cleft, one-cotyledon, and hole-insertion methods, which have high grafting positions, increase the separation between the scion and the ground and thereby decrease the likelihood of scion adventitious roots contracting soil-borne diseases (Hassell et al. 2008).

The grafting method initially used for melon was cleft grafting, but after the introduction of the tongue-approach grafting method its use diminished greatly (Kubota et al. 2008). In Italy, currently the one-cotyledon method and the holeinsertion method are used (Amadio 2004). In Spain, more than $90 \%$ of watermelon plants are grafted with the one-cotyledon method (Miguel and Maroto, 2000). Top-insertion grafting is the most popular method used in China, because it is suitable for use with Lagenaria and interspecific squash as rootstocks; it requires few materials, has high efficiency, and simpler management requirements than other methods (Lee and Oda 2003). Recently, Mohamed et al. (2014) reported that, compared with side grafting (SIG) or hole insertion grafting (HIG), tongue approach grafting (TAG) of watermelon yielded significantly enhanced: main stem length, numbers of lateral stems, numbers of male flowers per plant, fruit yield per plant, and fruit weight. However, numbers of leaves, numbers of female flowers per plant, and sex ratios were not significantly different among all grafting types. Of the three grafting methods tested, TAG seemed to be the best for watermelon. However, there also seemed to be an interaction between the grafting method and the rootstock used. Similar results were supported by the findings of Hassell et al. (2008), who suggested that TAG, which in general has a high survival rate, was chosen by inexperienced farmers although it required a great deal of space and labour.

\section{QUALITY AS AFFECTED BY GRAFTING}

The appearance of vegetables is a primary criterion in making purchasing decisions. Product appearance encompasses size, shape, colour, general condition, and absence of defects and decay. Textural traits are also very important in determining consumer acceptability. Thus, any external factor affecting these traits can modify the quality parameters of fresh produce, and can, therefore, lead to changes in final produce quality. It has been reported that grafting can affect fresh produce quality positively or negatively (Davis and Perkins-Veazie 2005-
2006, Flores et al. 2010, Rouphael et al. 2010). In the present review we will focus on quality of fruitvegetables from the families Cucurbitaceae and Solanaceae (Davis et al. 2008b, King et al. 2010): watermelon, melon, tomato, pepper and eggplants.

\section{Cucurbitaceae}

Watermelons (Citrullus lanatus L.) in the Mediterranean basin are most commonly handled under unrefrigerated conditions, and their shelf life at $10-15^{\circ} \mathrm{C}$ is $2-3$ weeks, depending on cultivar (Kyriacou and Soteriou 2012). Variations in grafted cucurbit fruit quality appear to depend on both rootstock and scion, which leads to contradictory reports in the literature. Under the best circumstances, and when specific rootstock/ scion combinations are used, grafting can enhance fruit external and/or internal quality (Davis and Perkins-Veazie 2005-2006, Alexopoulos et al. 2007). However, the most common complaints about grafted watermelon quality concern low Brix, insipid taste, increased numbers of yellowish bands in the red flesh, and internal flesh breakdown (Davis et al. 2008a). The primary sugars in watermelon are sucrose, fructose and glucose, and grafting can affect biochemical pathways that are related to sugar accumulation in the fruit; the low sugar content of grafted watermelon was correlated with low invertase, high sucrose synthase activity, low sucrose phosphate synthase activity, and low sugar transmembrane transport capability (Liu et al. 2006). The increase of sucrose in grafted plants was accompanied by increases in sucrose phosphate synthase and sucrose synthase activities (Xu et al. 2006a). In addition, it appears that sugar accumulation in mature fruits varies with rootstocks (Gao and Liao 2006, Xu et al. 2006b). In contrast to the reported increases in sugar content in grafted watermelons, the total sugar content of watermelons grafted onto bottle gourd rootstock was reported to be lower than that in self-rooted watermelons by Liu et al. (2006), who reported that grafting onto Cucurbita sp. rootstock decreased the quality of watermelon fruits, but that fruits from scions grafted onto bottle gourd rootstock differed only slightly from control fruits. Miguel et al. (2004) found no difference in concentrations of soluble solids in watermelon fruits from scions grafted onto a squash interspecific hybrid and those in control fruits. Davis et al. (2008a, b) demonstrated that grafting watermelon could increase lycopene and total carotenoids by $20 \%$, and increase amino acids, especially citrulline 
(a nonessential amino acid with vasodilation properties), by up to $35 \%$. Proietti et al. (2008) studied grafted and non-grafted control plants of mini-watermelon (Citrullus lanatus (Thunb.) Matsum. and Nakai), and found that: fruit quality parameters were similar in fruits from grafted and non-grafted plants; the titratable acidity (TA), juice electrical conductivity, TSS/TA ratio, and $\mathrm{K}$ and $\mathrm{Mg}$ concentrations were improved in fruits from grafted plants; lycopene, dehydroascorbate and total vitamin $\mathrm{C}$ contents were increased in grafted plants relative to controls by $40.5,13$ and $7.3 \%$, whereas spermidine and putrescine concentrations were reduced by 24 and 59\%, respectively; miniwatermelon fruits from plants grafted onto a Cucurbita moschata Poir. $\times$ Cucurbita maxima Duch. interspecific hybrid rootstock contained higher levels of $\mathrm{K}, \mathrm{Mg}$, lycopene and vitamin $\mathrm{C}$ than their respective control plants (Proietti et al. 2008).

Edelstein et al. (2014) found no difference between the total fruit quality indexes of non-grafted 'Extazy' mini-watermelon fruits and 'Extazy' fruits from plants grafted on various watermelon accessions; weights of fruits from plants grafted on Cucurbita rootstocks were higher than those of fruits from plants grafted on 'Extazy' or other watermelon accessions; no bitter flavour and no cucurbitacin were present in 'Extazy' fruits from plants grafted on bitter fruit watermelon accessions, indicating that the examined exotic watermelon accessions did not adversely affect fruit quality and could be used as a basic germplasm for watermelon rootstock breeding; the most promising accession was PI 296341 (Edelstein et al. 2014). Soteriou et al. (2014) used flesh reflectance colorimetry and mechanical texture analysis, and assessed $\mathrm{pH}$, titratable acidity (TA), and soluble solids (SS), soluble carbohydrates, lycopene and citrulline contents of watermelon fruits throughout ripening in grafted and self-rooted plants; they concluded that grafting affected both the quality and the ripening behaviour of watermelon fruits - the sweetness of the fruit, expressed in terms of SSC and total soluble carbohydrates content, was not affected by grafting, but acidity was moderately raised. Grafting improved physical quality attributes such as pulp firmness and colour and increased the fruit contents of important bioactive compounds such as lycopene and citrulline; however, as grafting retarded the ripening process, optimum harvest maturity in non-grafted plant was reached at $35-40$ days post-anthesis (dpa) compared with 40-45 dpa in grafted plants (Soteriou et al. 2014).

The physiological processes governing these changes in grafted plants have received much attention, but the molecular processes involved remain relatively unknown. Clearly, associated gene expression must be regulated at the transcriptional, post-transcriptional and post-translational levels in grafted plants. MicroRNAs (miRNAs) are a class of endogenous small non-coding RNAs involved in post-transcriptional gene regulation and they play a critical role in plant growth, development and stress responses. However, less is known about involvement of miRNAs in grafting behaviours, especially with regard to the watermelon crop. MiRNAs were expressed differentially when watermelon was grafted onto different rootstocks, suggesting that miRNAs might play an important role in divers biological and metabolic processes in watermelon, and that grafting may possibly change expression of miRNAs and thereby regulate plant growth and development, as well as mediating adaptation to stresses (Liu et al., 2013).

Melon (Cucumis melo L.) is one of the most economically important and widely cultivated vegetable crops in the Mediterranean region. The effectiveness of eight commercial rootstocks - 'RS 841', 'P 360', 'ES 99-13', 'Elsi' (Cucurbita maxima Duchesne $\times$ Cucurbita moschata Duchesne), and 'Belimo', 'Energia', 'Griffin', 'ES liscio' (Cucumis melo genotypes) - was evaluated under greenhouse conditions, in terms of productivity and fruit quality by Crino et al. (2007), who reported that fruit dry matter, TA and TSS contents, and fruit firmness and colour of grafted melons were similar to those of the plants grown on their own roots. Zhao et al. (2011) conducted explored the influence of grafting onto different rootstocks on ripening and quality attributes of 1-MCP-treated muskmelon fruits during postharvest storage, and found that grafting did not show a significant impact on fruit yield but affected the fruit shelf life significantly: fruits from non-grafted 'Athena' and 'Athena' grafted onto 'Strong Tosa' exhibited shelf lives of 31 and $22 \mathrm{~d}$ for the first and second harvests, respectively; shelf lives of fruits from self-grafted 'Athena' and 'Athena' grafted onto 'Tetsukabuto' declined by 6 and $3 \mathrm{~d}$, respectively, between the first and second harvests; as a result of grafting, whole fruit firmness decreased by an average of approximately $16 \%$ on days 13 to 31 , except for day 19 , but the effect was less with 'Strong Tosa' rootstock; mesocarp firmness of grafted 'Athena' melon was reduced by 
about $30 \%$ compared with that of non-grafted fruit on days 13 and 19; titratable acidity, soluble solids content, and ascorbic acid concentration were less affected by grafting (Zhao et al. 2011). RicárdezSalinas et al. (2010) reported that fruits harvested from grafted plants had firmness equal to that of those harvested from non-grafted plants, and the content of soluble solids was unaffected. Kolayli et al. (2010) investigated and compared chemical and biochemical properties of cultivated standard, hybrid, and grafted melons, according to $\mathrm{pH}$, Brix, antioxidant activity, total phenolics, ascorbic acid, individual phenolics, sugar, and organic acid values: the fructose/glucose ratio was three times as great in grafted as in standard melons; although the sugar alcohol mannitol was found in the standard and hybrid cultivars, it was absent from the grafted types; citric acid was found in the standard cultivar but not in the hybrid and grafted ones; the standard melon gained the highest score in terms of taste, because of its highest sweetness and sourness (Kolayli et al. 2010). Non-grafted, single-, and double-grafted melon plants of the cultivar Piel de Sapo were evaluated for yields and fruit quality in a long-term trial by San Bautista et al. (2011), who used the hybrid 'Shintoza' (C. maxima $\times$ C. moschata) as rootstock, and the cantaloupetype melon cultivar 'Sienne' as an intermediate scion; they found that double grafted plants gave greater fruit yields than simple-grafted and nongrafted plants - by 12 and $56 \%$, respectively - and their fruit quality, in terms of ${ }^{\circ}$ Brix and colour, were unaffected (San Bautista et al., 2011). Five Cucurbita maxima $\times$ Cucurbita moschata hybrids - 'Polifemo', 'AS10', 'RS841', 'P360' and 'Elsi' - and two genotypes of melon - 'Energia' and 'Sting' - selected for their disease resistance, were tested as rootstocks for melon cultivar 'Proteo' under greenhouse conditions. The contents of key aroma esters ethyl 2-methylbutanoate and ethyl butanoate were lower than in the controls in most of the grafted samples, by $20-55 \%$ and $63-95 \%$, respectively, except in fruits from the 'Proteo'/'Sting' grafting combination; the aromas of melons grafted on pumpkin hybrid and on 'Energia' rootstocks were more similar to the controls. The use of pumpkin-hybrid rootstocks elicited enhancements in the qualitative and quantitative carotenoid profiles, as expressed in lutein content in fruit samples from 'Elsi', 'P360', 'RS841' and 'AS10' grafting combinations, and in increased contents of $\beta$-carotene and $\alpha$-carotene - by about $56 \%$ - in 'P360' samples, whereas the melon genotype rootstocks elicited a decrease in the amount of $B$-carotene, by about $55 \%$ compared with the control. In a similar study, Verzera et al. (2014) used physical properties, chemical data, volatile constituents contents and sensory descriptors of four Cucurbita maxima $\times$ Cucurbita moschata hybrids - 'Polifemo', 'AS10', 'RS841' and 'P360' - and two melon genotypes - 'Energia' and 'Sting' - for quality determination. They found that the TA and TSS contents were similar among the samples, except for higher levels of TA in 'Incas'/'AS10' and 'Incas'/'Sting' combinations and higher TSS levels in 'Incas'/'AS10'. The contents of key aroma volatiles and aldehydes were lower than those in the controls in most of the grafted samples, by $20-60 \%$ and $8-45 \%$, respectively; 14 sensory descriptors were defined that encompassed appearance, aroma, taste, texture traits, flavour and overall quality (Verzera et al. 2014).

\section{Solanaceae}

Eggplant (Solanum melongena L.) is widely cultivated in tropical and temperate regions worldwide, and is amenable to grafting (Daunay 2008, King et al. 2010).

Gisbert et al. (2011) investigated effects of rootstock on fruit yield, apparent quality and proximate and mineral compositions of eggplant (Solanum melongena L.) 'Black Beauty' (BB) scions grafted on interspecific hybrid rootstocks developed from crosses of $S$. melongena with Solanum incanum L. (SI $\times \mathrm{SM})$ and Solanum aethiopicum L. $(\mathrm{SM} \times \mathrm{SA})$. The results were compared with those obtained with non-grafted (BB) controls and self-grafted (BB/BB) controls and with $S$. melongena 'Black Beauty' scions grafted onto Solanum torvum Sw. (STO) and Solanum macrocarpon L. (SMA) rootstocks. Little difference in apparent fruit-quality traits was observed among treatments, except for a greater fruit calyx length and greater prickliness of fruits grafted onto SMA rootstocks. Similar results were obtained for fruit composition: phenolics contents were higher in fruits from plants grafted onto SMA rootstocks than in those from STO rootstocks. Grafting eggplant onto interspecific eggplant hybrids, especially the SI $\times$ SM hybrid, has proved advantageous for eggplant production, because the high vigour and good rootstock/scion compatibility resulted in improved early and total yields, without apparently impairing fruit quality or composition (Gisbert et al. 2011). Seedlings of eggplant 'Rima' were used as scion (R) and control (non-grafted) 
and rootstock (self-grafted) (RR), and two hybrid tomatoes - 'Heman' (Lycopersicon hirsutm) and 'Primavera' (Lycopersicon esculentum) - were used as rootstocks. There were no significant differences among the four treatments, in $\mathrm{pH}$, BRIX (\%), acidity (\%) (Khah 2011). In addition, the fruit $\mathrm{Cu}, \mathrm{Mn}, \mathrm{Ca}, \mathrm{Zn}$ and $\mathrm{Fe}$ contents (ppm) did not significantly differ between the grafted and the control plants. Similar results were reported by Passam et al. (2005), who found that eggplants grafted onto two tomato rootstocks gave higher yields and bigger fruits than those of non-grafted plants, but the mineral compositions of fruits from grafted plants did not differ from those of nongrafted plants.

Arvanitoyannis et al. (2005) studied the physicochemical $(\mathrm{pH}$, mechanical firmness and vitamin $\mathrm{C}$ content) and sensory parameters of grafted and non-grafted eggplant plants, as affected by storage times of up to 17 days at $10^{\circ} \mathrm{C}$; plants of cultivar 'Tsakoniki' were grafted onto Solanum torvum and S. sisymbriifolium, and the fruits were stored under modified atmosphere packaging (MAP) conditions. Vitamin $\mathrm{C}$ content during storage was negatively affected by grafting, whereas MAP prolonged the shelf life. Flesh firmness was negatively affected by grafting and deteriorated during storage, but was positively affected by MAP. Sensory analysis obtained higher ratings for sweetness, acceptance and hardness among fruits from non-grafted plants, but no difference was detected for overall acceptance (Arvanitoyannis et al. 2005).

Moncada et al. (2013) evaluated the quality of eggplant cultivars 'Birgah', 'Black Bell', 'Black Moon' and 'Longo' grafted onto Solanum torvum or non-grafted. Grafting onto Solanum torvum changed the colour of fruits, making them darker and with less vivid colouring, but browning of inner tissue was not influenced by grafting. In addition, total phenolics content was greater in the non-grafted plants (Moncada et al. 2013). Oshiro et al. (2008) found that grafting increased the accumulation of scopolamine and atropine, which accumulated at toxic levels in fruits of eggplant grafted onto Datura inoxia P. Mill.

Tomato (Solanum lycopersicum (L.) Mill.) is one of the world's most popular and widely used vegetable crops (Mauromicale et al. 2011); in North America, over 40 million grafted tomato seedlings are estimated to be used annually (Kubota et al. 2008). The fruits of $S$. lycopersicum contain valuable nutritional components with antioxidant activity such as vitamin $\mathrm{C}$, carotenoid pigments, and phenolic compounds (Vinkovic Vrcek et al. 2011). The use of grafting for tomato production has increased in recent years because rootstocks improve tolerance of the plants to pathogens, poor water quality, over-wet soils, drought and toxic soil micronutrients ( $\mathrm{Wu}$ et al. 2007).

Vinkovic Vrcek et al. (2011) used the tomato cultivars 'Efialto', 'Heman' and 'Maxifort' as rootstocks, and 'Tamaris' as scion; grafting resulted in an increased number of marketable fruits per plant by $30 \%$, but the contents of vitamin $\mathrm{C}$ and total phenolics decreased significantly as a result of grafting. Also, the antioxidant activities of grafts differed significantly from those of their respective rootstocks. The overall results showed that tomato grafting on suitable rootstocks elicited positive effects on cultivation performance, but decreased tomato nutritional quality. Nicoletto et al. (2012) obtained similar results with respect to vitamin $\mathrm{C}$ reduction because of grafting.

Krumbein and Schwarz (2013) investigated whether grafting two scions - 'Piccolino' and 'Classy' - onto two commercial rootstocks 'Brigeor' and 'Maxifort' - could enhance the contents of carotenoids - lycopene and B-carotene - and flavour compounds - sugars, acids and aroma volatiles - in tomato fruits grown and harvested under 50\% shade; grafting 'Classy' onto 'Brigeor' decreased carotenoids by $8 \%$, resulting in decreases of three carotenoid-derived volatiles - geranylacetone, $\beta$-cyclocitral and $\beta$-ionone. Titratable acids were increased by both shading and grafting - by 9 and $6 \%$, respectively. In addition, lignin-derived volatiles such as methyl salicylate and guaiacol were enhanced in both scions by grafting.

Savvas et al. (2011) investigated the effects of grafting a commercial tomato hybrid onto three new commercial tomato rootstocks - 'Beaufort', 'He-Man', and 'Resistar' - with respect to plant growth, yield, and fruit quality, under low to moderate salt-stress conditions. With respect to fruit quality, salinity enhanced the TA, TSS, and ascorbic acid concentrations, but grafting and rootstock choice had no effect on any quality characteristics. Di Gioia et al. (2013) reported similar results: fruit contents of TSS, TA, and dry matter were unaffected by grafting at any salinity level. However, in a different study, Di Gioia et al. (2010) found that vitamin C contents decreased by $14-20 \%$ in the fruits of plants grafted onto 'Beaufort' $\mathrm{F}_{1}$ and 'Maxifort' $\mathrm{F}_{1}$, in comparison with the non-grafted treatment. 
Sweet pepper (Capsicum annuum L.) is one of the most important horticultural crops in many Mediterranean countries, where it is mostly grown in greenhouses. Bell pepper has high contents of vitamin $\mathrm{C}$, carotenes, phenols, capsaicinoids, xanthophylls, and flavonoids, in addition to exhibiting high antioxidant activity. These micronutrients impart to bell pepper qualities that have led to its use in traditional medicine against degenerative diseases, intestinal disorders, dysentery, and various problems related to mental health, among other ailments (Kouassi et al. 2012, Zhuang et al., 2012, Shotorbani et al., 2013).

Recently, Tsaballa et al. (2013) reported that pepper fruit shape was a characteristic found to be affected by grafting: working with graftings between two pepper genotypes (cultivars) differing in fruit shape, they observed fruit shape changes after grafting the round-shaped cultivar 'Mytilini Round' (scion) on the long-shaped cultivar, 'Piperaki Long' (rootstock). Furthermore, the phenotypic changes observed in scion fruits were inherited for two generations of seed-derived progenies, indicating that the changes imposed on the scion were heritable.

Chavez-Mendoza et al. (2013) evaluated the effects of the rootstock and the scion on the antioxidant activity and the contents of vitamin $\mathrm{C}$, total phenols, lycopene and $\beta$-carotene of bell peppers; they used the cultivars 'Fascinato' and 'Jeanette' as scion and 'Terrano' as rootstock. Their results indicated statistically significant differences in the contents of these bioactive compounds: between varieties, between grafted and nongrafted fruits, and between sampling dates. On average, grafting increased $\beta$-carotene and vitamin $\mathrm{C}$ concentrations and improved the antioxidant capacity, but had no influence on the total phenol or lycopene contents. They concluded that grafting to the rootstock 'Terrano' improved the nutritional quality of the fruits of both studied varieties.

Jang et al. (2013) examined the effects of grafting peppers (Capsicum annuum) onto various rootstocks, on fruit quality. Total marketable yields of 'Nokkwang', 'Saengsaeng Matkkwari', and 'Shinhong' were not significantly influenced by either autografting or grafting onto the five commercial rootstocks, whereas, in contrast, grafting influenced the apparent fruit quality of the peppers; the fruit characteristics varied according to the rootstock cultivars. However, the fruit characteristics of the rootstock did not affect those of the scion grafted onto that rootstock.
Leal-Fernandez et al. (2013) used the sweet pepper cultivar 'Triple Star' (Enza Zaden) as a non-grafted control, grafted onto the chilli pepper cultivar 'CM334', and onto the rootstocks, 'Tresor', 'AR96012', 'AR96023', 'AR96028', 'AR96029', 'AR96030', and 'Atlante' (Ramiro Arnedo). The best interaction was achieved with the 'AR96029' rootstock: compared with the non-grafted control, its marketable fruit number and weight were higher by 23.4 and $31.2 \%$, respectively. 'Tresor' ranked just below 'AR96029' in the number of marketable fruits, but without being significantly different. In contrast, the worst response was obtained with rootstock 'CM334', which showed significantly lower values of almost all of the variables, and reduced the productive potential of 'Triple Star', possibly because of incompatibility with the graft.

In some Mediterranean regions sweet pepper crop yields and quality are negatively affected by the high radiation and temperature during the springsummer harvesting period. Although the use of shading screens is common, the use of grafting onto adequate rootstocks could be an interesting alternative means to maintain commercial fruit yield and quality under unshaded conditions; López-Marín et al. (2013) found that, compared with non-grafted plants, grafting increased the total and marketable fruit yields by 30 and $50 \%$ under unshaded and shaded conditions, respectively. However, grafting did not influence TA or TSS contents.

\section{CONCLUSIONS}

For decades, grafting has been successfully practised in many Asian countries, and it is becoming increasingly popular worldwide. However, the range of commercial rootstocks is limited, and the effects of unexamined rootstocks on vegetable quality are still not clear. Among the main problems associated with grafting are: the time and labour required; cost - grafted seedlings are more expensive than non-grafted ones (Djidonou et al. 2013); rendering of rootstocks ineffective by newly emerging soil-borne diseases or pests; and changes in fruit quality. Therefore, it is difficult for farmers to provide the intensive care required to raise newly grafted plants, which often requires the added cost of a transplant facility equipped with healing chambers, and of trained personnel. However, improved grafting methods that should reduce the labour costs for grafting and subsequent handling of plug-grown grafted transplants will 
contribute further to the increased use of grafted vegetables worldwide.

Although efficient grafting machines and robots are becoming available, which can increase grafting speed and increase the survival rate of grafted plants, purchasing of grafted seedlings will become more affordable (Taylor et al. 2006). Therefore, further research needs to focus on rootstock development, improvement of grafting robots efficiency (Tian et al. 2013), and development of acclimatization facilities, in order to reduce costs and increase grafting success. However, although mechanization and automation can help address large-scale production issues, investment in machinery and automation imposes considerable upfront costs, and growers cannot move specialized grafting machinery to other jobs or "lay off" the machines during the off-season, as they can with personnel. The optimal mix of labour and automation must be determined through careful planning and analysis at the design stage - planning that includes consideration of stochastic factors such as the demand for or benefits of grafted seedlings, and the cost of grafting equipment (Meng et al. 2014). Another problem is posed by the need to predict grafting compatibility in order to improve grafting success. Grafts cause stress in plants that can be measured by changes in chlorophyll (Chl) fluorescence (Calatayud et al. 2006). Recently, Calatayud et al. (2013) showed that application of chlorophyll fluorescence imaging (CFI) measurements can be very useful in monitoring compatibility/incompatibility of grafted plants, in order to identify changes in plant performance. However, this process must involve extensive investigation of the various combinations of rootstock and scion cultivars, in order to provide satisfactory calibration of the changes in fluorescence parameters that follow plant grafting.

In this review, we have evaluated the effects of grafting on vegetable postharvest quality, including physical properties, flavour, and health-related contents of the product. Our understanding of the effects of grafting on vegetable quality is far from complete: there are many conflicting reports on changes in fruit quality attributable to grafting, and on whether effects of grafting are advantageous or deleterious. Rootstock/scion combinations need to be carefully selected for specific climatic and geographic conditions; however, unfortunately, most of the rootstocks available in the market have been selected especially for disease resistance and vigour, so that breeding programmes are needed, to select rootstock/scion combinations with high fruitquality attributes under various growing conditions (Davis et al. 2008a, b, Cohen et al. 2014). The agronomical and physiological processes that affect the fruit quality of grafted plants have received much research attention, but the biochemical and molecular processes involved remain relatively unknown. Therefore, in-depth investigations should be conducted with the aim of providing biochemical and molecular knowledge and biomarkers that will lead to improved rootstock/scion compatibility, and to providing proper environmental conditions to facilitate rootstock and scion union. Moreover, although many studies on the effects of grafting on visual appearance, texture, and contents of taste compounds such as sugars and acids in vegetable crops have been conducted, to our knowledge research on sensorily important aroma volatiles has not been pursued so far. Furthermore, limited research has addressed the effects of grafting on important nutritional compounds. Thus, the identification of rootstocks and rootstock/scion combinations with positive impacts on fruit quality, especially with regard to health-promoting compounds forms a basic requirement for the continued success of grafting. Finally, researchers, extension specialists, and industries need to work together to integrate this modern technology as an effective tool for producing high-quality vegetables and for sustainable horticultural production worldwide.

\section{ACKNOWLEDGEMENTS}

Contribution from the Agricultural Research Organization, the Volcani Center, Bet Dagan, Israel, No. 699/14.

\section{REFERENCES}

Alexopoulos A.A., Kondylis A., Passam H.C., 2007. Fruit yield and quality of watermelon in relation to grafting. J. Food Agric. Environ. 5: T178-179.

Aloni B., Cohen R., Karni L., Akas H., Edelstein M., 2010. Hormonal signaling in rootstock-scion interactions. Sci. Hortic. 127: 119-126.

Amadio A., 2004. Alternatives to methyl bromide adopted for cucurbit production in projects funded by Montreal Protocol. Proc. Fifth International Conference on Alternatives to Methyl Bromide, Lisbon: 71-74.

Arvanitoyannis I.S., Khah E.M., Christakou E.C., Bletsos F.A., 2005. Effect of grafting and modified atmosphere packaging on eggplant quality parameters during storage. Intl. J. Food Sci. Technol. 40: $311-322$ 
Bekhradi F., Kashi A., Delshad M., 2011. Effect of three cucurbits rootstocks on vegetative and yield of 'Charleston Gray' watermelon. Intl. J. Plant Prod. 5: 105-110.

Calatayud A., Roca D., Martínez P. F., 2006. Spatialtemporal variations in rose leaves under water stress conditions studied by chlorophyll fluorescence imaging. Plant Physiol. Biochem. 44: 564-573.

Calatayud A., San Bautista A., Pascual B., Marotob J.V., López-Galarza S., 2013. Use of chlorophyll fluorescence imaging as diagnostic technique to predict compatibility in melon graft. Sci. Hortic. 149: 13-18.

Chávez-Mendoza C., Sánchez E., Carvajal-Millán E., Muñoz-Márquez E., Guevara-Aguilar A., 2013. Characterization of the nutraceutical quality and antioxidant activity in bell pepper in response to grafting. Molecules 18: 15689-15703.

Cohen R., Tyutyunik J., Fallik E., Oka Y., Tadmor Y., Edelstein M., 2014. Phytopathological evaluation of exotic watermelon germplasm as a basis for rootstock breeding. Sci. Hort. 165: 203-210.

Colla G., Rouphael Y., Leonardi C., Bie Z., 2010. Role of grafting in vegetable crops grown under saline conditions. Sci. Hort. 127: 147-155.

Crino P., Lo Bianco C., Rouphael Y., Colla G., Saccardo F., Paratore A., 2007. Evaluation of rootstock resistance to Fusarium wilt and gummy stem blight and effect on yield and quality of a grafted 'Inodorus' melon. Hort. Sci. 42: 521-525.

Daunay M. C., 2008. Eggplant. In: Handbook of Plant Breeding: Vegetables II. J. Prohens and F. Nuez (eds), Springer, New York, USA: 163-220.

Davis A. R., Perkins-Veazie P., 2005-2006. Rootstock effects on plant vigor and watermelon fruit quality. Cucurbit Genet. Coop. Rep. 28-29: 39-42.

Davis A. R., Perkins-Veazie P., Hassell R., Levi A., King S. R., Zhang W., 2008a. Grafting effects on vegetable quality. Hort. Sci. 43: 1670-1672.

Davis A. R., Perkins-Veazie P., Sakata Y., LópezGalarza S., Maroto J. V., Lee S. G., et al., 2008 b. Cucurbit grafting. Crit. Rev. Plant Sci. 27: 50-74.

Di Gioia F., Serio F., Buttaro D., Ayala O., Santamaria P., 2010. Influence of rootstock on vegetative growth, fruit yield and quality in 'Cuore di Bue', an heirloom tomato. J. Hort. Sci. Biotechnol. 85: 477-482.

Di Gioia F., Signore A., Serio F., Santamaria P., 2013. Grafting improves tomato salinity tolerance through sodium partitioning within the shoot. Hort. Sci. 48: 855-862.

Disdonou D., Gao Z., Zhao X., 2013. Economic analysis of grafted tomato production in sandy soils in northern Florida. HortTechnology 23: 613-621.

Edelstein M., Tyutyunik J., Fallik E., Meir A., Tadmor Y., CoHen R., 2014. Horticultural evaluation of exotic watermelon germplasm as potential rootstocks. Sci. Hort. 165: 196-202.
Flores F. B., Sanchez-Bel P., Estan M. T., MartinezRodriguez M. M., Moyano E., Morales B., et al., 2010. The effectiveness of grafting to improve tomato fruit quality. Sci. Hort. 125: 211-217.

Gao J. H., Liao H. J., 2006. Effect of grafting on watermelon quality. China Cucurbits Veg. 5: 12-14.

Gisbert C., Prohens J., Raigón M. D., Stommel J. R., NuEz F., 2011. Eggplant relatives as sources of variation for developing new rootstocks: Effects of grafting on eggplant yield and fruit apparent quality and composition. Sci. Hort. 128: 14-22.

Hassell R.L., Memmott F., Lierce D.J., 2008. Grafting methods for watermelon production. HortScience 43: $1677-1679$.

JAng Y., Moon J.-H., Lee J.-W., Lee S. G., Kim S. Y., Chun C., 2013. Effects of different rootstocks on fruit quality of grafted pepper (Capsicum annuum L.). Korean J. Hort. Sci. Technol. 31: 687-699.

Кнан Е., 2011. Effect of grafting on growth, performance and yield of aubergine (Solanum melongena L.) in greenhouse and open-field. Intl. J. Plant Prod. 5: 359-366.

King S.R., Davis A.R., Zhang X., Crosby K., 2010. Genetics, breeding and selection of rootstocks for Solanaceae and Cucurbitaceae. Sci. Hort. 127: 106-111.

Kolayli S., Kara M., Tezcan F., Erim B., Sahin H., Ulusoy S., Aliyazicioglu R., 2010. Comparative study of chemical and biochemical properties of different melon cultivars: standard, hybrid, and grafted melons. J. Agric. Food Chem. 58: 9764-9769.

Kouassi K.C., Koffi-Nevry R., Guillaume L.Y., Yéssé Z.N., Koussémon M., Kablan T., Athanase K.K., 2012. Profiles of bioactive compounds of some pepper fruit (Capsicum L.) varieties grown in Côte D'Ivoire. Innovat. Rom. Food Biotechnol. 11: 23-31.

Krumbein A., Schwarz D., 2013. Grafting: A possibility to enhance health-promoting and flavour compounds in tomato fruits of shaded plants? Sci. Hort. 149: 97-107.

Kuвота C., 2008. Use of grafted seedlings for vegetable production in North America. Acta Hort. 770: 21-28.

Kubota C., Mcclure M.A., Kokalis-Burelle N., Bausher M.G., Rosskopf E.N., 2008. Vegetable grafting: History, use, and current technology status in North America. Hort. Sci. 43: 1664-1669.

Kyriacou M.C., Soteriou G.A., 2012. Postharvest change in compositional, visual and textural quality of grafted watermelon cultivars. Acta Hort. 934: 985-991.

Leal-Fernández C., Godoy-Hernández H., NúÑezColín C.A., Anaya-López J.A., Villalobos-Reyes S., Castellanos J.Z., 2013. Morphological response and fruit yield of sweet pepper (Capsicum annuum L.) grafted onto different commercial rootstocks. Biol. Agric. Hortic. 29: 1-11. 
LeE J.M., OdA M., 2003. Grafting of herbaceous vegetable and ornamental crops. Hort. Rev. 28: 61-124.

Lee J.-M., Kubota C., Tsao S.J., Bie Z., Echevarria P.H., Morra L., Oda M., 2010. Current status of vegetable grafting: diffusion, grafting techniques, automation. Sci. Hortic. 127: 93-105.

Liu H.Y., Zhu Z. J., Diao M., Guo Z. P., 2006. Characteristic of the sugar metabolism in leaves and fruits of grafted watermelon during fruit development. Plant Physiol. Commun. 42: 835-840.

Liu N., Yang J.-H., Guo S.-G., Xu Y., Zhang M.-F., 2013. Genome-wide identification and comparative analysis of conserved and novel microRNAs in grafted watermelon by high-throughput sequencing. PLOS ONE 8: 1-13.

López-Marín J., González A., Pérez-Alfocea F., EgeaGilabert C., Fernández J.A., 2013. Grafting is an efficient alternative to shading screens to alleviate thermal stress in greenhouse-grown sweet pepper. Sci. Hort. 149: 39-46.

Louws F.J., Rivard C.L., Kubota C., 2010. Grafting fruiting vegetables to manage soilborne pathogens, foliar pathogens, arthropods and weeds. Sci. Hort. 127: $127-146$.

Mauromicale G., Longo A.M.G., Lo Monaco A., 2011. The effect of organic supplementation of solarized soil on the quality of tomato fruit. Sci. Hort. 129: 189-196.

Meng C., Xu D., Son Y.-J., Kubota C., Lewis M., Tronstad R., 2014. An integrated simulation and AHP approach to vegetable grafting operation design. Comp. Electron. Agric. 102: 73-84.

Miguel A., Maroto J.V., 2000. Nuevas técnicas en el cultivo de la sandía (Citrullus lanatus (Thunb.) Matsum. and Nakai). Consellería de Agricultura, Pesca y Alimentación de la Generalitat Valenciana y Fundación Caja Rural Valencia. 37-38.

Miguel A., Maroto J.V., San Bautista A., Baixauli C., Cebolla V., Pascual B., López, S., Guardiola, J. L., 2004. The grafting of triploid watermelon is an advantageous alternative to soil fumigation by methyl bromide for control of Fusarium wilt. Sci. Hort. 103: 9-17.

Mohamed F.H., Abd El-Hamed K.E., Elwan M.W.M., Hussien M.N.E., 2014. Evaluation of different grafting methods and rootstocks in watermelon grown in Egypt. Sci. Hort. 168: 145-150.

Moncada A., Miceli A., Vetrano F., Mineo V., Planeta D., D'Anna F., 2013. Effect of grafting on yield and quality of eggplant (Solanum melongena L.). Sci. Hort. 149: 108-114.

Nicoletto C., Tosini F., SAmbo P., 2013. Effect of grafting and ripening conditions on some qualitative traits of 'Cuore di bue' tomato fruits. J. Sci. Food Agric. 93: 1397-1403.

Oshiro N., Kuniyoshi K., Nakamura A., Araki Y., Tamanaha K., Inafuku Y., 2008. A case of food poisoning due to ingestion of eggplant, Solanum melongena, grafted on devil's trumpet, Datura metel. Shokuhin Eiseigaku Zasshi 49: 376-379 [in Japanese].

Passam H.C., Stylianoy M., Kotsiras A., 2005. Performance of eggplant grafted on tomato and eggplant rootstocks. Eur. J. Hort. Sci. 70: 130-134.

Proietti S., Rouphael Y., Colla G., Cardraelli M., De Agazio M., Zacchini M., Rea E., Moscatello S., Battistelli A., 2008. Fruit quality of miniwatermelon as affected by grafting and irrigation regimes. J. Sci. Food. Agric. 88: 1107-1114.

Ricárdez-Salinas M., Huitrón-Ramírez M.V., TelloMarquina J.C., Camacho-Ferre F., 2010. Planting density for grafted melon as an alternative to methyl bromide use in Mexico. Sci. Hort. 126: 236-241.

Rouphael Y., Schwarz D., Krumbein A., Colla G., 2010. Impact of grafting on product quality of fruit vegetables. Sci. Hort. 127: 172-179.

San Bautista A., Calatayud A., Nebauer S.G., Pascual B., Maroto J.V., López-Galarza S., 2011. Effects of simple and double grafting melon plants on mineral absorption, photosynthesis, biomass and yield. Sci. Hort. 130: 575-580.

Sánchez-Rodríguez E., Leyva R., Constán-Aguilar C., Romero L., Ruiz J.M., 2014. How does grafting affect the ionome of cherry tomato plants under water stress? Soil Sci. Plant Nutr. 60: 145-155.

Savvas D., Colla G., Rouphae, Y., Schwarz D., 2010. Amelioration of heavy metal and nutrient stress in fruit vegetables by grafting. Sci. Hort. 127: 156-161.

Savvas D., Savva A., Ntatsi G., Ropokis A., Karapanos I., Krumbein A., Olympios C., 2011. Effects of three commercial rootstocks on mineral nutrition, fruit yield, and quality of salinized tomato. J. Plant Nutr. Soil Sci. 174: 154-162.

Schwarz D., Rouphael Y., Colla G., Venema J.H., 2010. Grafting as a tool to improve tolerance of vegetables to abiotic stresses: thermal stress, water stress and organic pollutants. Sci. Hort. 127: 162-171.

Shotorbani N., Jamei R., Heidari R., 2013. Antioxidant activities of two sweet pepper Capsicum annuum L. varieties phenolics extracts and the effects of thermal treatment. Avicenna J. Phytomed. 3: 25-34.

Soteriou G.A., Kyriacou M.C., Siomos A.S., Gerasopoulos D., 2014. Evolution of watermelon fruit physicochemical and phytochemical composition during ripening as affected by grafting. Food Chem. 165: 282-289.

Taylor M., Bruton B., Fish W., Roberts W., 2006. Economics of grafted vs conventional watermelon plants. Hort. Sci. 41: 519-520.

Temperini O., Calabrese N., Temperini A., Rouphael Y., Tesi R., Lenzi A., Carito A., Colla G., 2013. Grafting artichoke onto cardoon rootstocks: Graft compatibility, yield and Verticillium wilt incidence. Sci. Hort. 149: 22-27. 
Tian S.B., Ashraf M.A., Kondo N., Shiıg T., Momin M.A., 2013. Optimization of machine vision for tomato grafting robot. Sensor Lett. 11: 1190-1194.

Tsaballa A., Athanasiadis C., Pasentsis K., Ganopoulos I., Nianiou-Obeidat I., Tsaftaris A., 2013. Molecular studies of inheritable grafting induced changes in pepper (Capsicum annuum) fruit shape. Sci. Hort. 149: 2-8.

Verzera A., Dima G., Tripodi G., Condurso C., Crinò P., Romano D., Mazzaglia A., Lanza C. M., Restuccia C., Paratore A., 2014. Aroma and sensory quality of honeydew melon fruits (Cucumis melo L. subsp. melo var. inodorus H. Jacq.) in relation to different rootstocks. Sci. Hort. 169: 118-124.

Vinkovic Vrcek I., Samobor V., Bojic M., MedicSaric M., Vukobratovic M., Erhatic R., Horvat D., Matotan Z., 2011. The effect of grafting on the antioxidant properties of tomato (Solanum lycopersicum L.). Span. J. Agric. Res. 9: 844-851.
Wu C.-C., Chang Y.-C., Chiu Y.-C., 2007. Study on physiological metabolism of tomato grafted seedlings. J. Taiwan Soc. Hort. Sci. 53: 195-203.

Xu C. Q., Li T. L., Qi H. Y., 2006a. Effects of grafting on development, carbohydrate content, and sucrose metabolizing enzymes activities of muskmelon fruit. Acta Hort. Sinica 33: 773-778.

Xu C. Q., Li T. L., Qi H. Y., Wang H., 2006b. Effects of grafting on development and sugar content of muskmelon fruit. J. Shenyang Agric. Univ. 37: 378381.

Zhao X., Guo Y., Huber D.J., Lee J., 2011. Grafting effects on postharvest ripening and quality of 1-methylcyclopropene-treated muskmelon fruit. Sci. Hort. 130: 581-587.

Zhuang Y., Chen L., Sun L., Cao J., 2012. Bioactive characteristics and antioxidant activities of nine peppers. J. Funct. Foods 4: 331-338.

Received July 7, 2014; accepted October 24, 2014 